\title{
Clinical Implications of Urinary C-Peptide Creatinine Ratio in Patients with Different Types of Diabetes
}

\author{
Yanai Wang $(\mathbb{D}$, Ying Gao, Xiaoling Cai $\mathbb{D}$, Ling Chen, Lingli Zhou $(\mathbb{D}$, Yumin Ma, Siqian Gong, \\ Xueyao Han $\mathbb{D}$, and Linong Ji
}

\begin{abstract}
Departments of Endocrinology and Metabolism, Peking University People's Hospital, Peking University Diabetes Center, Beijing 100044, China

Correspondence should be addressed to Xueyao Han; xueyaohan@sina.com and Linong Ji; prof_jilinong@aliyun.com
\end{abstract}

Received 21 April 2019; Accepted 19 July 2019; Published 7 August 2019

Academic Editor: Hiroshi Okamoto

Copyright (C) 2019 Yanai Wang et al. This is an open access article distributed under the Creative Commons Attribution License, which permits unrestricted use, distribution, and reproduction in any medium, provided the original work is properly cited.

\begin{abstract}
Introduction. Urinary C-peptide creatinine ratio (UCPCR) is used as a marker of endogenous insulin secretion. This study aims to assess the effectiveness of UCPCR for distinguishing between type 1 diabetes (T1DM) and non-T1DM (monogenic diabetes and T2DM) and predicting therapeutic choices in type 2 diabetes (T2DM) patients. Methods. Twenty-three patients with genetically confirmed monogenic diabetes (median age 35.0 years (interquartile range 30.0-47.0), 13 (56.5\%) men), 56 patients with T1DM (median age 46.0 years (interquartile range 26.5-59.5), 28 (50.0\%) men), 136 patients with T2DM (median age 53.0 years (interquartile range 42.0-60.0), 87 (64.0\%) men), and 59 healthy subjects (median age 36.0 years (30.0-42.0), 26 (44.1\%) men) were included. UCPCR was collected in the morning. Receiver operating characteristic (ROC) curves were used to identify optimal UCPCR cut-off values to differentiate T1DM from non-T1DM. This UCPCR cut-off was used to divide T2DM patients into two groups, and the two groups were compared. Results. The UCPCR was lower in patients with T1DM compared with T2DM, monogenic diabetes, and healthy subjects, while the UCPCR was similar in T2DM and monogenic diabetes. A UCPCR cut-off of $\geq 0.21 \mathrm{nmol} / \mathrm{mmol}$ distinguished between monogenic diabetes and T1DM (area under the curve [AUC], 0.949) with $87 \%$ sensitivity and $93 \%$ specificity. UCPCR $\geq 0.20 \mathrm{nmol} / \mathrm{mmol}$ had $82 \%$ sensitivity and $93 \%$ specificity for distinguishing between T2DM and T1DM, with an AUC of 0.932. UCPCR was not reliable for distinguishing between monogenic diabetes and T2DM (AUC, 0.605). Twenty-five of 136 (18.4\%) T2DM patients had UCPCR $\leq 0.20 \mathrm{nmol} / \mathrm{mmol}$. Compared with T2DM patients with a UCPCR $>0.20 \mathrm{nmol} / \mathrm{mmol}$, T2DM patients with UCPCR $\leq 0.20 \mathrm{nmol} / \mathrm{mmol}$ had a lower serum C-peptide (fasting C-peptide, $0.39 \mathrm{nmol} / \mathrm{L}$ vs. $0.66 \mathrm{nmol} / \mathrm{L}, P<0.001$; postprandial C-peptide, $0.93 \mathrm{nmol} / \mathrm{L}$ vs. $1.55 \mathrm{nmol} / \mathrm{L}, P<0.001$ ), lower BMI $\left(22.8 \mathrm{~kg} / \mathrm{m}^{2}\right.$ vs. $\left.25.2 \mathrm{~kg} / \mathrm{m}^{2}, P=0.006\right)$, and higher percentage of insulin or secretagogue therapy $(92.0 \%$ vs. $59.5 \%$, $P=0.002$ ). Conclusions. UCPCR is a practical and noninvasive marker that can distinguish between TIDM and T2DM or monogenic diabetes. UCPCR $\leq 0.20 \mathrm{nmol} / \mathrm{mmol}$ reflects severe impaired beta cell function and the need for insulin or secretagogue therapy in T2DM patients.
\end{abstract}

\section{Introduction}

Classification of diabetes remains a challenge for endocrinologists, especially in young patients [1]. Typical clinical symptoms and laboratory tests are the main method of differentiating between types of diabetes. However, with the increase in childhood obesity, the onset age of T2DM is earlier and the number of T1DM patients with either normal weight or overweight has increased. As reported, among newly diagnosed diabetes patients $\leq 19$ years old, only two-thirds were T1DM patients in the USA [2]. Therefore, body mass index (BMI) and onset age of diabetes may currently be less specific for distinguishing between T1DM and T2DM $[3,4]$.

Maturity-onset diabetes of the young (MODY) is the most common monogenic diabetes, accounting for $~ 2 \%$ of all diabetes $[5,6]$. The population prevalence of MODY in the United Kingdom is estimated to be 68 to 108 cases per million [7]. MODY can be easily confused with T1DM because of the early onset age of diabetes and lack of obesity. 
Additionally, simple family history and insulin resistance markers did not reliably distinguish between MODY and T2DM in adults [7-9]. Farmer and Fox reported that only about $15 \%$ of young diabetes patients had been correctly diagnosed [10]. Misdiagnosis leads to improper insulin prescription, and it may have a significant impact on quality of life and long-term health outcomes [8].

Serum C-peptide is widely used to assess islet beta cell function, and it is helpful for individualizing treatment in diabetes. The half-life of C-peptide is $20-30 \mathrm{~min}$, which is much longer than that of insulin (half-life, 3-5 min) [11]. C-peptide is mostly metabolized by the kidneys. Urinary C-peptide (UCP) quantity reflects $5-10 \%$ of the total $\mathrm{C}$-peptide that is secreted by islet beta cells [12]. Twentyfour-hour UCP was proposed as a noninvasive measure to screen insulin deficiency and as an additional tool to improve clinical classification of diabetes [13]. Because of its time dependence, $24 \mathrm{~h} \mathrm{UCP}$ is less convenient than spot UCPCR. Fasting UCPCR was shown to be well correlated with $24 \mathrm{~h}$ UCP ( $r=0.8, P=0.00006)$ [14], which suggests that fasting UCPCR might be an easy method to evaluate C-peptide secretion. Moreover, in the past decade, UCPCR was reported to distinguish between T1DM and non-T1DM (i.e., T2DM and MODY) with a high sensitivity and specificity [15-17]. However, research on UCPCR in diabetes classification has been infrequent in East Asia, and it is not clear whether UCPCR can be used to guide individualized treatment of patients with T2DM.

We aimed to assess whether UCPCR can distinguish between T1DM and monogenic diabetes, including hepatocyte nuclear factor 1- $\alpha$ maturity-onset diabetes of the young (MODY3), mitochondrial diabetes (MIDD), and T2DM, and to determine whether UCPCR is a useful tool for predicting therapeutic choices in T2DM patients in a Chinese population.

\section{Materials and Methods}

2.1. Subjects. We recruited $56 \mathrm{~T} 1 \mathrm{DM}$ patients (fasting serum C-peptide $(\mathrm{FCP})<0.2 \mathrm{nmol} / \mathrm{L}$, ketosis-onset and insulindependent treatment within 6 months from onset or adult onset, positive islet autoantibodies, and insulin-dependent insulin treatment), 23 patients with monogenic diabetes (ten patients with HNF1A variants (A311D, p.P353L, R263C, T10M, P379A, R131W, R131W, R200W, ivs8+1, and Q324Term) that induced diabetes (MODY3), 13 patients with mitochondrial A3243G mutation-induced diabetes (MIDD)), and 136 T2DM patients from Peking University People's Hospital, Beijing, China. Type 2 diabetes was defined as adult nonketosis onset diabetes with negative islet autoantibodies (glutamate decarboxylase antibody, insulin antibody, and islet cell antibody).

Diabetes was diagnosed in accordance with the 1999 World Health Organization (WHO) criteria. Patients with monogenic diabetes were included if they had known causative variants and a confirmed molecular genetic diagnosis. The research team used standardized questionnaires to obtain the following information: age, sex, age at diagnosis of diabetes, family history of diabetes, diabetic complications, and current medication. We measured the waistline (WL), blood pressure, weight, and height of every patient. The subjects with an estimated glomerular filtration rate (eGFR) $<60 \mathrm{~mL} / \mathrm{min} / 1.73 \mathrm{~m}^{2}$ or hypoglycemia during $24 \mathrm{~h}$ urine sample collection were excluded.

The healthy subjects were selected based on the following standards: (1) normal blood glucose: no history of diabetes, fasting blood glucose $(\mathrm{FBG})<6.1 \mathrm{mmol} / \mathrm{L}, 75 \mathrm{~g}$ oral glucose tolerance test (OGTT) $2 \mathrm{~h}<7.8 \mathrm{mmol} / \mathrm{L}$, and HbA1c $(\mathrm{A} 1 \mathrm{C})<6.0 \%$; (2) blood pressure: lack of hypertension history, systolic pressure $(\mathrm{SBP})<140 \mathrm{mmHg}$, and diastolic pressure $(\mathrm{DBP})<90 \mathrm{mmHg}$; (3) $\mathrm{BMI}<24 \mathrm{~kg} / \mathrm{m}^{2}$; (4) $\mathrm{WL}$ male $<90 \mathrm{~cm}$ and female $<85 \mathrm{~cm}$; (5) normal blood lipids: no history of hyperlipidemia, cholesterol $(\mathrm{CHO})<6.2$ $\mathrm{mmol} / \mathrm{L}$, triglycerides (TGs) $<1.7 \mathrm{mmol} / \mathrm{L}$, low-density lipoprotein-cholesterol $(\mathrm{LDL}-\mathrm{C})<4.1 \mathrm{mmol} / \mathrm{L}$, male highdensity lipoprotein-cholesterol $(\mathrm{HDL}-\mathrm{C}) \geq 0.9 \mathrm{mmol} / \mathrm{L}$, and female $\mathrm{HDL}-\mathrm{C} \geq 1.0 \mathrm{mmol} / \mathrm{L}$; (6) normal liver function: alanine aminotransferase $(\mathrm{ALT}) \leq 50 \mathrm{U} / \mathrm{L}$, aspartate aminotransferase (AST) $\leq 40 \mathrm{U} / \mathrm{L}$; (7) normal renal function: male creatinine $<104 \mu \mathrm{mol} / \mathrm{L}$ and female creatinine $<84 \mu \mathrm{mol} / \mathrm{L}$; (8) blood uric acid: males $<428 \mu \mathrm{mol} / \mathrm{L}$ and females $<357 \mu \mathrm{mol} / \mathrm{L}$; (9) urinary albumin/creatinine ratio (ACR) < $30 \mathrm{mg} / \mathrm{g}$; (10) leukocytes $>4 \times 10^{9} / \mathrm{L}$; (11) hemoglobin: males $\geq 120 \mathrm{~g} / \mathrm{L}$ and females $\geq 110 \mathrm{~g} / \mathrm{L}$; and (12) no history of hyperuricemia.

Written informed consent was obtained from all subjects. This study was conducted in accordance with the Declaration of Helsinki and was approved by the Ethics Committee at Peking University People's Hospital, Beijing, China.

2.2. Sample Collection. Urine and blood samples after 8-12 hours of fasting were collected in the morning. Blood samples at $2 \mathrm{~h}$ after breakfast were also collected. The urine samples were stored at $-80^{\circ} \mathrm{C}$ and assayed on the same day. Blood samples were tested on the collecting day.

2.3. Laboratory Methods. Urinary C-peptide was measured using an electrochemiluminescence immunoassay on a Roche Diagnostics Cobas e601 analyzer in the endocrine department at the People's Hospital of Peking University, Beijing, China. The lower limit of the C-peptide assay was $0.03 \mathrm{nmol} / \mathrm{L}$. Urinary creatinine was analyzed on the Roche Cobas e311 platform using creatinine Jaffé reagent, and the results were used to calculate UCPCR ( $\mathrm{nmol} / \mathrm{mmol})$. For the purpose of the analysis, all UCP values $<0.03 \mathrm{nmol} / \mathrm{L}$ were coded as $0.03 \mathrm{nmol} / \mathrm{L}$.

2.4. Statistical Analysis. Results are presented as the median (interquartile range (IQR)), unless otherwise stated. Characteristics of patients with monogenic diabetes, T1DM, T2DM, or healthy subjects were compared using a chi-squared test for categorical data (e.g., sex, treatment, and parental history), and the Mann-Whitney $U$ test for continuous variables for data that were not normally distributed (age at diagnosis, diabetes duration, FCP, postprandial C-peptide (PCP), TG, and UCPCR) were used. Additionally, an independent sample $t$-test was used for the normally distributed variables, and a one-way analysis of variance (ANOVA) 


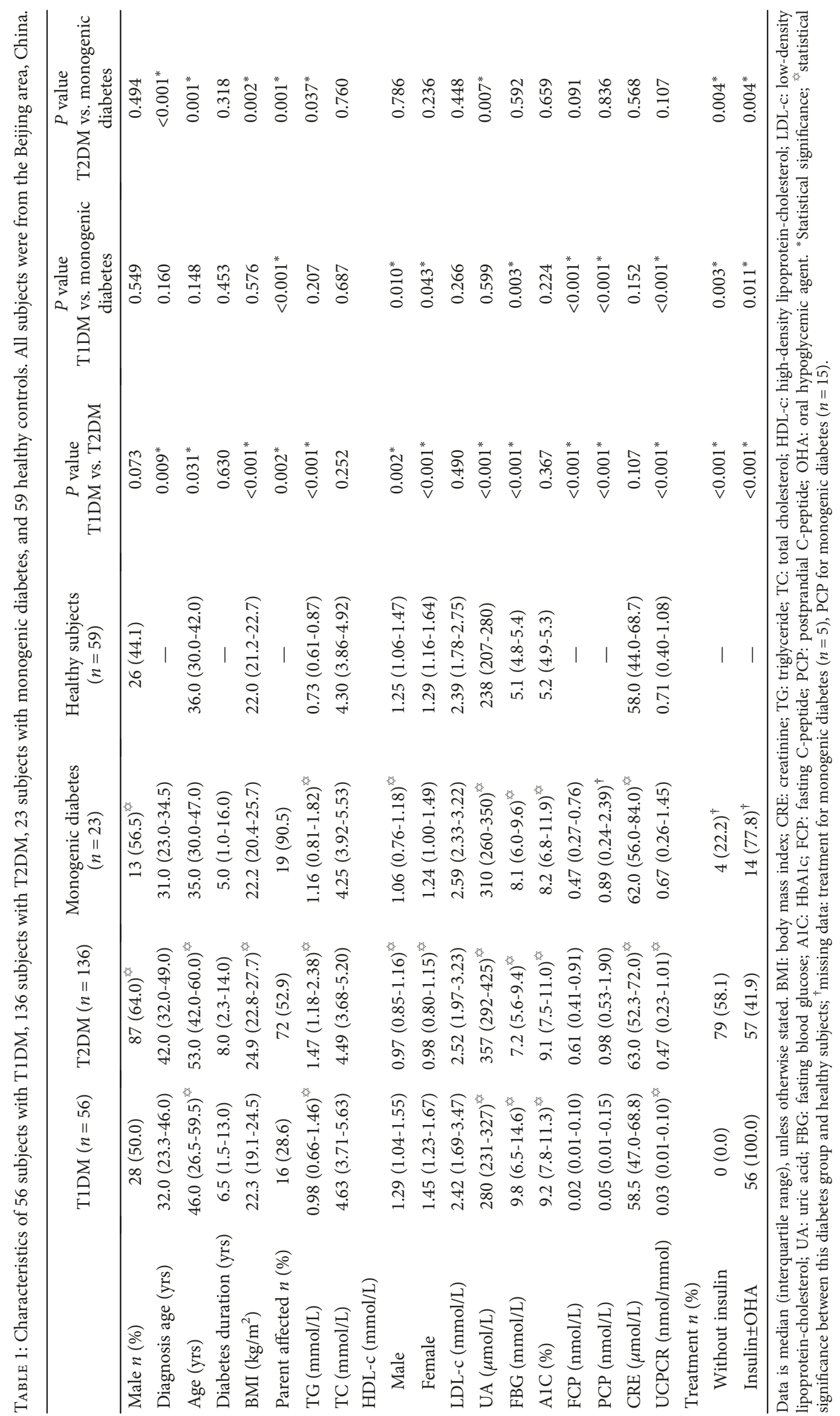




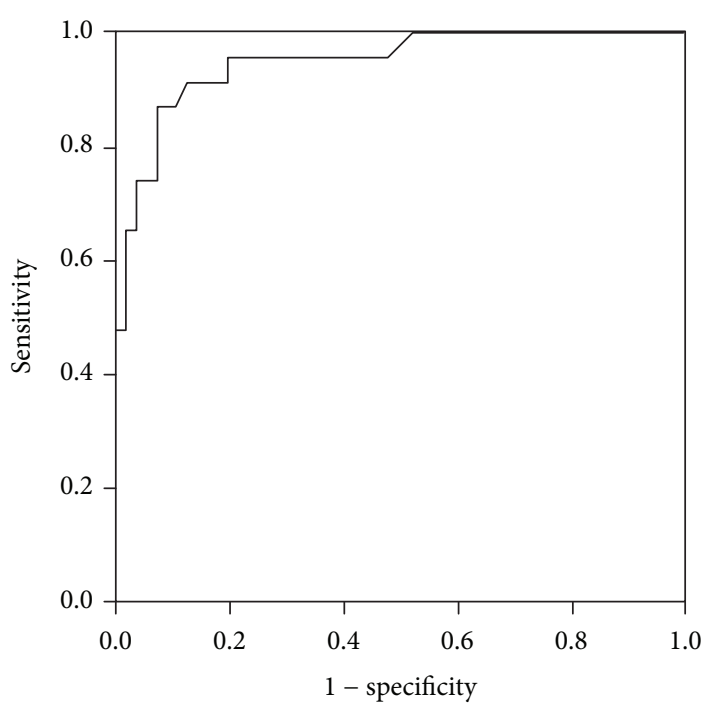

(a)

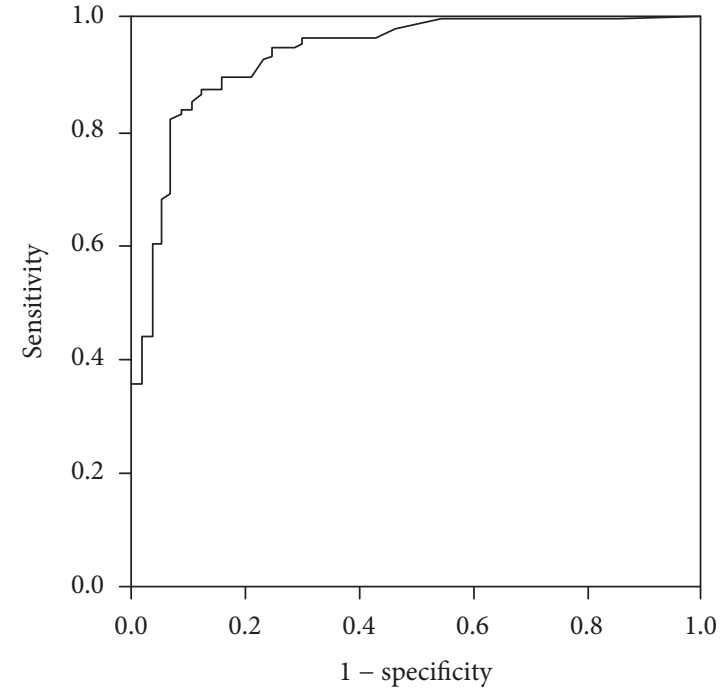

(b)

FIgure 1: ROC curve to identify T1DM from non-T1DM. (a) The ROC curve identified a cut-off UCPCR $\geq 0.21 \mathrm{nmol} / \mathrm{mmol}$ for discriminating monogenic diabetes from T1DM (AUC 0.949) with $87 \%$ sensitivity and $93 \%$ specificity. (b) The ROC curve identified a cut-off UCPCR $\geq 0.20 \mathrm{nmol} / \mathrm{mmol}$ for discriminating T2DM from T1DM (AUC 0.932 ) with $82 \%$ sensitivity and $93 \%$ specificity.

followed by the subsequent LSD (Least-Significant Difference) test was used for comparisons between two groups. ROC curves were used to identify cut-off values of UCPCR that provided the optimal sensitivity and specificity (maximizing the Youden index) for distinguishing monogenic diabetes and T2DM from T1DM. $P<0.05$ was considered to be significant. Statistical software SPSS 16.0 was used for the statistical analysis. Statistical software MedCalc V15.2 was used for comparing different ROC curves of serum C-peptide and UCPCR.

\section{Results}

3.1. Clinical Characteristics of the Study Participants. All patient characteristics are presented in Table 1. T1DM patients were younger and slimmer than T2DM, and they received insulin treatment. The onset age of T2DM was older compared with the other two diabetes groups. Parental diabetes was most prevalent in patients with MODY. There were no statistical differences in diabetes duration among diabetes groups.

3.2. The Comparison of UCPCR among Different Types of Diabetes. The UCPCR was lower in the T1DM group compared with T2DM (median (IQR), 0.03 (0.01-0.10) $\mathrm{nmol} / \mathrm{mmol}$ vs. $0.47(0.23-1.01) \mathrm{nmol} / \mathrm{mmol}, P<0.001)$ and monogenic diabetes groups $(0.67(0.26-1.45) \mathrm{nmol} / \mathrm{mmol}$, $P<0.001)$. The UCPCR was similar in the T2DM and monogenic diabetes groups $(P=0.099)$. The UCPCR was higher in healthy subjects $(0.71(0.40-1.08) \mathrm{nmol} / \mathrm{mmol})$ compared with those with T1DM $(P<0.001)$ or T2DM $(P<0.001)$, but it was similar to those with monogenic diabetes.
3.3. The Performance of UCPCR in Distinguishing between T1DM and Non-T1DM. UCPCR distinguishes between T1DM and monogenic diabetes. UCPCR $\geq 0.21 \mathrm{nmol} / \mathrm{mmol}$ had the highest Youden index for identifying monogenic diabetes, with $87 \%$ sensitivity and $93 \%$ specificity (AUC, 0.949 , 95\% confidence interval (CI) $(0.898-1.000), P<0.001$; Figure 1). UCPCR did not reliably distinguish between monogenic diabetes and type 2 diabetes (AUC, 0.605, 95\% CI (0.474-0.736), $P=0.107) . \quad$ UCPCR $\geq 0.20 \mathrm{nmol} /$ mmol distinguished between T2DM and T1DM with $82 \%$ sensitivity and $93 \%$ specificity (AUC, 0.932, 95\% CI (0.893-0.971), $P<0.001$; Figure 1).

We compared the ROC curves between UCPCR and serum C-peptide in distinguishing T1DM and non-T1DM by the software MedCalc V15.2 (difference of areas under the curve between serum C-peptide and UCPCR was $0.0619, Z$ statistic was 0.348 , and $P=0.7279$ ).

3.4. The Clinical Characteristics of T2DM Patients with $U C P C R \leq 0.2 \mathrm{nmol} / \mathrm{mmol}$. The characteristics of T2DM patients are presented in Table 2. Twenty-five of 136 (18.4\%) T2DM patients had UCPCR $\leq 0.20 \mathrm{nmol} / \mathrm{mmol}$. Compared with T2DM patients with a UCPCR $>0.20$ $\mathrm{nmol} / \mathrm{mmol}$, those with UCPCR $\leq 0.20 \mathrm{nmol} / \mathrm{mmol}$ had a lower BMI (22.8 (21.2-25.4) $\mathrm{kg} / \mathrm{m}^{2}$ vs. $25.2(23.5-28.0)$ $\left.\mathrm{kg} / \mathrm{m}^{2}, P=0.006\right)$, FCP $(0.39(0.26-0.61) \mathrm{nmol} / \mathrm{L}$ vs. 0.66 $(0.47-0.96) \quad \mathrm{nmol} / \mathrm{L}, \quad P<0.001), \quad$ PCP $(0.93 \quad(0.58-1.23)$ $\mathrm{nmol} / \mathrm{L}$ vs. $1.55(0.97-2.13) \mathrm{nmol} / \mathrm{L}, P<0.001)$, and UA (308 $\quad(235-370) \quad \mu \mathrm{mol} / \mathrm{L}$ vs. $372 \quad(302-436) \quad \mu \mathrm{mol} / \mathrm{L}$, $P=0.011)$ and a higher proportion of insulin or secretagogue therapy $(23 / 25(92.0 \%)$ vs. $66 / 111(59.5 \%), P=0.002)$. Characteristics of the two patients who had a UCPCR $<0.20 \mathrm{nmol} / \mathrm{mmol}$ and who were using oral hypoglycemic agents are presented in Table 3. The ratios of male, insulin 
TABLE 2: Clinical characteristics of T2DM patients with UCPCR $\leq 0.2 \mathrm{nmol} / \mathrm{mmol}$ vs. T2DM patients with UCPCR $>0.2 \mathrm{nmol} / \mathrm{mmol}$.

\begin{tabular}{|c|c|c|c|}
\hline & $\begin{array}{c}\mathrm{UCPCR} \leq 0.2 \mathrm{nmol} / \mathrm{mmol} \\
n=25\end{array}$ & $\begin{array}{c}\mathrm{UCPCR}>0.2 \mathrm{nmol} / \mathrm{mmol} \\
n=111\end{array}$ & $P$ value \\
\hline Male $n(\%)$ & $18(72.0)$ & $69(62.2)$ & 0.355 \\
\hline Diagnosis age (yrs) & $42.5(33.0-48.5)$ & $42.0(32.0-49.0)$ & 0.838 \\
\hline Age (yrs) & $56.0(41.5-61.0)$ & $53.0(42.0-60.0)$ & 0.548 \\
\hline Diabetes duration (yrs) & $9.5(4.0-14.3)$ & $7.0(2.0-14.0)$ & 0.365 \\
\hline $\operatorname{BMI}\left(\mathrm{kg} / \mathrm{m}^{2}\right)$ & $22.8(21.2-25.4)$ & $25.2(23.5-28.0)$ & $0.006^{*}$ \\
\hline $\mathrm{SBP}(\mathrm{mmHg})$ & $126(120-140)$ & $129(120-138)$ & 0.785 \\
\hline DBP (mmHg) & $80(70-80)$ & $76(68-80)$ & 0.435 \\
\hline \multicolumn{4}{|l|}{$\mathrm{WL}(\mathrm{cm})$} \\
\hline Male & $92(79-98)$ & $95(88-98)$ & 0.066 \\
\hline Female & $83(78-90)$ & $89(81-97)$ & 0.370 \\
\hline $\mathrm{TG}(\mathrm{mmol} / \mathrm{L})$ & $1.28(1.07-2.12)$ & $1.55(1.21-2.58)$ & 0.111 \\
\hline $\mathrm{TC}(\mathrm{mmol} / \mathrm{L})$ & $4.81(3.74-5.66)$ & $4.40(3.68-5.09)$ & 0.064 \\
\hline \multicolumn{4}{|l|}{ HDL-c (mmol/L) } \\
\hline Male & $1.03(0.92-1.16)$ & $0.96(0.85-1.16)$ & 0.812 \\
\hline Female & $1.01(0.73-1.20)$ & $0.96(0.81-1.14)$ & 0.725 \\
\hline LDL-c (mmol/L) & $2.81(2.01-3.60)$ & $2.49(1.94-3.11)$ & 0.371 \\
\hline $\mathrm{UA}(\mu \mathrm{mol} / \mathrm{L})$ & $308(235-370)$ & $372(302-436)$ & $0.011^{*}$ \\
\hline FBG $(\mathrm{mmol} / \mathrm{L})$ & $7.4(5.7-9.6)$ & $7.1(5.6-9.4)$ & 0.606 \\
\hline FCP (nmol/L) & $0.39(0.26-0.61)$ & $0.66(0.47-0.96)$ & $<0.001^{*}$ \\
\hline $\mathrm{PCP}(\mathrm{nmol} / \mathrm{L})$ & $0.93(0.58-1.23)$ & $1.55(0.97-2.13)$ & $<0.001^{*}$ \\
\hline UCPCR (nmol/mmol) & $0.11(0.08-0.15)$ & $0.57(0.37-1.14)$ & $<0.001^{*}$ \\
\hline $\mathrm{A} 1 \mathrm{C}(\%)$ & $9.7(7.5-12.0)$ & $9.1(7.5-10.9)$ & 0.294 \\
\hline \multicolumn{4}{|l|}{ Complications } \\
\hline $\mathrm{DN} n(\%)$ & 0 & $10(9.0)$ & 0.256 \\
\hline $\mathrm{DR} n(\%)$ & $5(20.0)$ & $15(13.5)$ & 0.607 \\
\hline DPN $n(\%)$ & $9(36.0)$ & $35(31.5)$ & 0.666 \\
\hline \multicolumn{4}{|l|}{ Treatment $n(\%)$} \\
\hline Insulin/secretagogues & $23(92.0)$ & $66(59.5)$ & $0.002^{*}$ \\
\hline
\end{tabular}

Data is median (interquartile range), unless otherwise stated. BMI: body mass index; SBP: systolic blood pressure; DBP: diastolic blood pressure; WL: waistline; TG: triglyceride; TC: total cholesterol; HDL-c: high-density lipoprotein-cholesterol; LDL-c: low-density lipoprotein-cholesterol; UA: uric acid; FBG: fasting blood glucose; FCP: fasting C-peptide; PCP: postprandial C-peptide; A1C: HbA1c; DN: diabetic nephropathy; DR: diabetic retinopathy; DPN: diabetic peripheral neuropath. *Statistical significance.

treatment, and complications and the levels of TC, TG, HDL-c, LDL-c, FBG, and A1C were similar in the two groups.

\section{Discussion}

4.1. Main Findings. Our study showed that UCPCR is a noninvasive tool that can be used to distinguish between T1DM and non-T1DM (T2DM and monogenic diabetes). UCPCR can distinguish between monogenic diabetes patients who need further genetic testing and who likely need noninsulin treatment and T1DM patients. However, in this study, UCPCR was not useful in distinguishing between monogenic diabetes and T2DM. Another important finding in our study is that the cut-off $(\leq 0.20 \mathrm{nmol} / \mathrm{mmol})$ for a differential diagnosis of diabetes is also helpful in identifying patients who need insulin or secretagogue therapy added to their treatment regimen to achieve their goal of glucose control. To the best of our knowledge, this is the first report on UCPCR in East Asia.

4.2. UCPCR Differs between Patients with T1DM, T2DM, and Healthy Subjects. In our study, UCPCR was lower in T1DM compared with T2DM or monogenic diabetes patients and healthy subjects. On the one hand, Besser et al. and Sebahat et al. demonstrated similar postprandial UCPCR results in T1DM, T2DM, and MODY subjects [15-17]. On the other hand, FCP in the T1DM group was also lower than that in T2DM and monogenic diabetes. Thus, we ascribed the lower UCPCR in T1DM patients to their absolute insulin deficiency pathogenesis.

UCPCR in monogenic diabetes was similar to that of healthy subjects in this study, but considering hyperglycemia in monogenic diabetes patients, we can speculate that there were relatively more dysfunctional beta cells in monogenic 
TABLE 3: The characters of the two patients who had a UCPCR $<0.20 \mathrm{nmol} / \mathrm{mmol}$ and without insulin or secretagogue treatment.

\begin{tabular}{lcc}
\hline & Patient 1 & Patent 2 \\
\hline Sex & Male & Female \\
Diagnosis age $(\mathrm{yrs})$ & 29 & 60 \\
Age $(\mathrm{yrs})$ & 29 & 73 \\
Diabetes duration $(\mathrm{yrs})$ & 0.6 & 13 \\
BMI $\left(\mathrm{kg} / \mathrm{m}^{2}\right)$ & 21.9 & 19.5 \\
SBP $(\mathrm{mmHg})$ & 96 & 135 \\
DBP $(\mathrm{mmHg})$ & 60 & 70 \\
WL $(\mathrm{cm})$ & 68 & 78 \\
TG $(\mathrm{mmol} / \mathrm{L})$ & 2.93 & 0.61 \\
TC $(\mathrm{mmol} / \mathrm{L})$ & 6.4 & 5.69 \\
HDL-c $(\mathrm{mmol} / \mathrm{L})$ & 1.10 & 1.92 \\
LDL-c $(\mathrm{mmol} / \mathrm{L})$ & 3.90 & 2.73 \\
UA $(\mu \mathrm{mol} / \mathrm{L})$ & 292 & 194 \\
FBG $(\mathrm{mmol} / \mathrm{L})$ & 9.4 & 5.13 \\
FCP $(\mathrm{nmol} / \mathrm{L})$ & 0.60 & 0.3 \\
PCP $(\mathrm{nmol} / \mathrm{L})$ & 0.71 & 1.77 \\
FINS $(\mu \mathrm{U} / \mathrm{ml})$ & 2.72 & 31.18 \\
PINS $(\mu \mathrm{U} / \mathrm{ml})$ & 5.92 & 8.20 \\
UCPCR $(\mathrm{nmol} / \mathrm{mmol})$ & 0.11 & 0.11 \\
A1C $(\%)$ & 13.5 & 6.6 \\
Complications & & \\
DN $n(\%)$ & - & - \\
DR $n(\%)$ & - & - \\
DPN $n(\%)$ & + \\
Treatment $n(\%)$ & & \\
& &
\end{tabular}

Metformin $500 \mathrm{mg}$ t.i.d. Metformin $250 \mathrm{mg}$ t.i.d. Acarbose tablet $50 \mathrm{mg} \quad$ Acarbose tablet $50 \mathrm{mg}$ t.i.d. t.i.d.

Data is median (interquartile range), unless otherwise stated. BMI: body mass index; SBP: systolic blood pressure; DBP: diastolic blood pressure; WL: waistline; TG: triglyceride; TC: total cholesterol; HDL-c: high-density lipoprotein-cholesterol; LDL-c: low-density lipoprotein-cholesterol; UA: uric acid; FBG: fasting blood glucose; FCP: fasting C-peptide; PCP: postprandial C-peptide; A1C: HbA1c; DN: diabetic nephropathy; DR: diabetic retinopathy; DPN: diabetic peripheral neuropath; OHA: oral hypoglycemic agent. *Statistical significance.

diabetes patients compared with healthy controls and that more sensitive methods such as a glucagon stimulation test would reveal these results. Additionally, patients who were taking secretagogues may confound this result, and the small sample size in our study might be another explanation.

4.3. The Advantages of UCPCR in the Evaluation of Beta Cell Function. Both UCPCR and serum C-peptide can be used to assess pancreatic beta cell function even with insulin microsecretors [18]. Compared with serum C-peptide, which should be separated from the serum via centrifugation and subsequently frozen to avoid protease hydrolysis, UCPCR was more convenient [11]. UCP is still stable even if it stays at room temperature for 3 days in boric acid [14] or if it is frozen at $-80^{\circ} \mathrm{C}$ for 4 months (we tested 20 samples in an unpublished study). The stability and noninvasiveness of UCPCR can potentially facilitate many other experiments.
4.4. The Performance of UCPCR in the Differential Diagnosis of Different Diabetes Subtypes. UCPCR has been reported widely for measurement of endogenous insulin secretion and to distinguish between diabetes subtypes [15-17, 19]. Sebahat et al. reported that postprandial UCPCR $\geq 0.22$ $\mathrm{nmol} / \mathrm{mmol}$ could distinguish MODY from T1DM in children with $96.3 \%$ sensitivity and $85.7 \%$ specificity [17]. The cut-off point was similar to our result, which seemed more specific but less sensitive. Besser et al. performed several studies on UCPCR. They also demonstrated that UCPCR $\geq 0.20$ $\mathrm{nmol} / \mathrm{mmol}$ distinguished between MODY1 or MODY3 and T1DM with a sensitivity of $97 \%$ and a specificity of $96 \%$ in long-term adult diabetes patients (diabetes duration $>5$ years) [15]. An absolute insulin deficiency appeared in most T1DM patients with a disease duration of more than 5 years [20], and therefore, the above-mentioned reports, which included mainly long-term T1DM patients (diabetes duration, 6.5 years (median, our study); $5.8 \pm 3.3$ years (mean \pm SD, Sebahat et al.'s study); $>5$ years (Besser et al.'s study)), had similar optimal UCPCR cut-off levels. When a diabetes duration $>2$ years is taken into consideration, the cut-off for the postprandial UCPCR level for typing nonT1DM (MODY, T2DM) and T1DM in children changed to $0.7 \mathrm{nmol} / \mathrm{mmol}$ (97\% sensitivity and 96\% specificity) [16].

UCPCR did not reliably distinguish between MODY and T2DM (AUC, 0.605) in our study, and Besser et al. reported a similar result [16]. This may be because a rapid decline in pancreas beta cell function is infrequent in both T2DM and monogenic diabetes.

4.5. UCPCR in Guiding the Individualized Treatments of T2DM Patients. In clinical practice, FCP is an important index for endocrinologists to use in deciding upon different therapies. There was already some evidence about the validity of C-peptide in predicting the time and intensity of insulin treatment [21, 22]. A stimulated C-peptide concentration $\leq 0.20 \mathrm{nmol} / \mathrm{L}$ may be a signal of absolute insulin deficiency and the likely requirement for future insulin treatment or even a predictor of intensive therapy [23]. Hope et al. reported that the urinary $\mathrm{C}$-peptide creatinine ratio $>0.20 \mathrm{nmol} / \mathrm{mmol}$ in a mixed-meal tolerance test was a reliable indicator of retained endogenous insulin secretion [19].

In our study, 25/136 (18.4\%) T2DM patients had a $\mathrm{UCPCR} \leq 0.20 \mathrm{nmol} / \mathrm{mmol}$. Hope et al. reported that $11 / 191$ (5.8\%) T2DM patients had UCPCR $\leq 0.20 \mathrm{nmol} / \mathrm{mmol}$ in a mixed-meal tolerance test. The patients in our study and Hope et al.'s study with UCPCR $\leq 0.20 \mathrm{nmol} / \mathrm{mmol}$ had a similar duration of disease as patients in our study ( 9.5 vs. 12 years), but the patients in our study were thinner $\left(22.8\right.$ vs. $\left.25.1 \mathrm{~kg} / \mathrm{m}^{2}\right)$.

In this study, most T2DM patients who had UCPCR $\leq 0.20 \mathrm{nmol} / \mathrm{mmol}(92.0 \%)$ were treated with insulin or secretagogues. They also had lower FCP and PCP compared with the patients with UCPCR $>0.20 \mathrm{nmol} / \mathrm{mmol}$, which indicates a more deranged beta cell function in these patients. Two of $25(8.0 \%)$ patients who had a UCPCR $\leq 0.20 \mathrm{nmol} / \mathrm{mmol}$ were treated without insulin or secretagogues, and both of these patients did not show signs of insulin resistance. These patients may need insulin or 
secretagogues in the future when their glucose control worsens because their hyperglycemia is likely caused by absolute insulin deficiency rather than insulin resistance. A recent study on the relationship between different T2DM diabetes subgroups and outcomes showed that the severely insulindeficient subgroup had the highest risk of retinopathy [24]. Thus, UCPCR is very helpful for identifying patients who have poor glucose control and need early addition of insulin or secretagogues to their treatment regimen.

4.6. Limitations. To distinguish T1DM from T2DM with inadequate glycemic control might be problematic since glucotoxicity might cause suppressed insulin and C-peptide. There was a possibility that T2DM patients with very low UCPCR were composed of a few T1DM patients with negative islet antibodies. In this case, repeating UCPCR measurements in these patients when good glycemic control is achieved is necessary. Our study was a single-center study with relatively small sample size. Further studies are necessary to extend the validity of our findings.

\section{Conclusion}

The UCPCR is a practical noninvasive marker for the identification of TIDM from T2DM or monogenic diabetes which needs further gene diagnosis. The UCPCR $\leq 0.20$ $\mathrm{nmol} / \mathrm{mmol}$ could reflect severely impaired beta cell function and a need for insulin or secretagogues in T2DM patients.

\section{Data Availability}

The datasets during and/or analyzed during the current study are available from the corresponding authors on reasonable request.

\section{Conflicts of Interest}

Wang Yanai, Gao Ying, Cai Xiaoling, Chen Ling, Zhou Lingli, Ma Yumin, Gong Siqian, Han Xueyao, and Ji Linong declare that they have no conflict of interest.

\section{Authors' Contributions}

The following authors, Wang Yanai, Cai Xiaoling, Chen Ling, Zhou Lingli, Ma Yumin, Gong Siqian, Han Xueyao, and Ji Linong, served as principal investigators for this study and participated in patient selection and sample collection. Gao Ying was responsible for the testing of UCPCR. All authors read and approved the final manuscript.

\section{Acknowledgments}

This research was supported by the Beijing Municipal Commission of Science and Technology funds (Nos. Z141100007414002 and D131100005313008) and the National Key Research and Development Program (No. 2016YFC1304901).

\section{References}

[1] T. J. McDonald and S. Ellard, "Maturity onset diabetes of the young: identification and diagnosis," Annals of Clinical Biochemistry: An International Journal of Biochemistry and Laboratory Medicine, vol. 50, no. 5, pp. 403-415, 2013.

[2] SEARCH for Diabetes in Youth Study Group, "The burden of diabetes mellitus among US youth: prevalence estimates from the SEARCH for Diabetes in Youth study," Pediatrics, vol. 118, no. 4, pp. 1510-1518, 2006.

[3] P. Zeitler, "Update on nonautoimmune diabetes in children," The Journal of Clinical Endocrinology \& Metabolism, vol. 94, no. 7, pp. 2215-2220, 2009.

[4] D. Dabelea, E. J. Mayer-Davis, S. Saydah et al., "Prevalence of type 1 and type 2 diabetes among children and adolescents from 2001 to 2009 ," JAMA, vol. 311, no. 17, pp. 1778-1786, 2014.

[5] E. Schober, B. Rami, M. Grabert et al., "Phenotypical aspects of maturity-onset diabetes of the young (MODY diabetes) in comparison with type 2 diabetes mellitus (T2DM) in children and adolescents: experience from a large multicentre database," Diabetic Medicine, vol. 26, no. 5, pp. 466-473, 2009.

[6] H. M. Ledermann, "Is maturity onset diabetes at young age (MODY) more common in Europe than previously assumed?" The Lancet, vol. 345, no. 8950, p. 648, 1995.

[7] G. Thanabalasingham and K. R. Owen, "Diagnosis and management of maturity onset diabetes of the young (MODY)," BMJ, vol. 343, no. 3, article d6044, 2011.

[8] C. Pihoker, L. K. Gilliam, S. Ellard et al., "Prevalence, characteristics and clinical diagnosis of maturity onset diabetes of the young due to mutations in HNF1A, HNF4A, and glucokinase: results from the SEARCH for Diabetes in Youth," The Journal of Clinical Endocrinology \& Metabolism, vol. 98, no. 10, pp. 4055-4062, 2013.

[9] C. Bellanné-Chantelot, D. J. Lévy, C. Carette et al., "Clinical characteristics and diagnostic criteria of maturity-onset diabetes of the young (MODY) due to molecular anomalies of the HNF1A gene," The Journal of Clinical Endocrinology and Metabolism, vol. 96, no. 8, pp. E1346-E1351, 2011.

[10] A. Farmer and R. Fox, "Diagnosis, classification, and treatment of diabetes," BMJ, vol. 342, no. 4, article d3319, 2011.

[11] P. M. Clark, "Assays for insulin, proinsulin(s) and C-peptide," Annals of Clinical Biochemistry: An International Journal of Biochemistry and Laboratory Medicine, vol. 36, no. 5, pp. 541-564, 1999.

[12] D. L. Horwitz, A. H. Rubenstein, and A. I. Katz, "Quantitation of human pancreatic beta-cell function by immunoassay of C-peptide in urine," Diabetes, vol. 26, no. 1, pp. 30-35, 1977.

[13] H. J. Gjessing, L. E. Matzen, O. K. Faber, and A. Frøland, "Fasting plasma C-peptide, glucagon stimulated plasma C-peptide, and urinary C-peptide in relation to clinical type of diabetes," Diabetologia, vol. 32, no. 5, pp. 305-311, 1989.

[14] T. J. McDonald, B. A. Knight, B. M. Shields, P. Bowman, M. B. Salzmann, and A. T. Hattersley, "Stability and reproducibility of a single-sample urinary C-peptide/creatinine ratio and its correlation with 24-h urinary C-peptide," Clinical Chemistry, vol. 55, no. 11, pp. 2035-2039, 2009.

[15] R. E. J. Besser, M. H. Shepherd, T. J. McDonald et al., "Urinary C-peptide creatinine ratio is a practical outpatient tool for identifying hepatocyte nuclear factor $1-\alpha /$ hepatocyte nuclear factor 4- $\alpha$ maturity-onset diabetes of the young from 
long-duration type 1 diabetes," Diabetes Care, vol. 34, no. 2, pp. 286-291, 2011.

[16] R. E. Besser, B. M. Shields, S. E. Hammersley et al., "Home urine C-peptide creatinine ratio (UCPCR) testing can identify type 2 and MODY in pediatric diabetes," Pediatric Diabetes, vol. 14, no. 3, pp. 181-188, 2013.

[17] S. Y. Agladioglu, E. Sagsak, and Z. Aycan, "Urinary C-peptide/creatinine ratio can distinguish maturity-onset diabetes of the young from type 1 diabetes in children and adolescents: a single-center experience," Hormone Research in Poediatrics, vol. 84, no. 1, pp. 54-61, 2015.

[18] R. A. Oram, A. G. Jones, R. E. J. Besser et al., "The majority of patients with long-duration type 1 diabetes are insulin microsecretors and have functioning beta cells," Diabetologia, vol. 57, no. 1, pp. 187-191, 2014.

[19] S. V. Hope, A. G. Jones, E. Goodchild et al., "Urinary C-peptide creatinine ratio detects absolute insulin deficiency in type 2 diabetes," Diabetic Medicine, vol. 30, no. 11, pp. 1342-1348, 2013.

[20] J. P. Palmer, G. A. Fleming, C. J. Greenbaum et al., "C-peptide is the appropriate outcome measure for type 1 diabetes clinical trials to preserve $\beta$-cell function: report of an ADA workshop, 21-22 October 2001," Diabetes, vol. 53, no. 1, pp. 250-264, 2004.

[21] S. Madsbad, T. Krarup, P. McNair et al., "Practical clinical value of the C-peptide response to glucagon stimulation in the choice of treatment in diabetes mellitus," Acta Medica Scandinavica, vol. 210, no. 1-6, pp. 153-156, 1981.

[22] M. Landin-Olsson, K. O. Nilsson, A. Lernmark, and G. Sundkvist, "Islet cell antibodies and fasting C-peptide predict insulin requirement at diagnosis of diabetes mellitus," Diabetologia, vol. 33, no. 9, pp. 561-568, 1990.

[23] M. W. Steffes, S. Sibley, M. Jackson, and W. Thomas, “ $\beta$-cell function and the development of diabetes-related complications in the Diabetes Control and Complications Trial," Diabetes Care, vol. 26, no. 3, pp. 832-836, 2003.

[24] E. Ahlqvist, P. Storm, A. Käräjämäki et al., "Novel subgroups of adult-onset diabetes and their association with outcomes: a data-driven cluster analysis of six variables," The Lancet Diabetes \& Endocrinology, vol. 6, no. 5, pp. 361-369, 2018. 


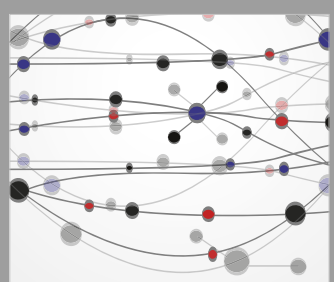

The Scientific World Journal
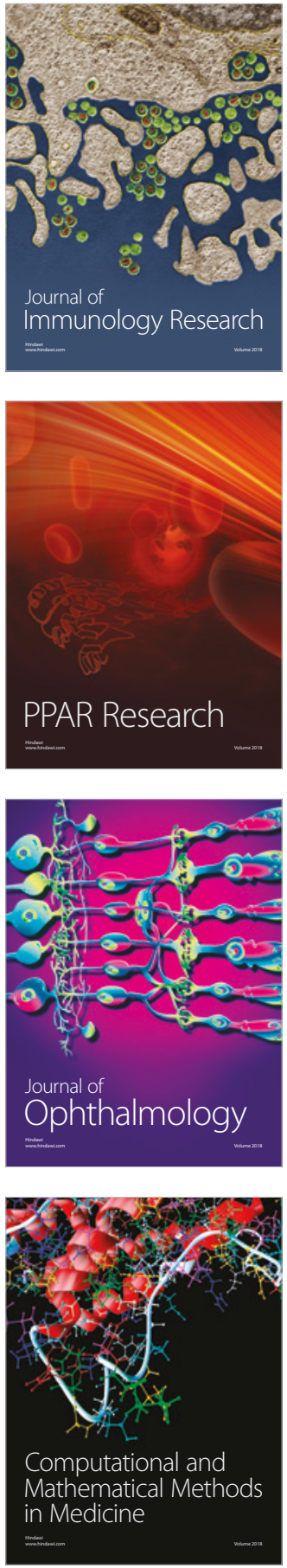

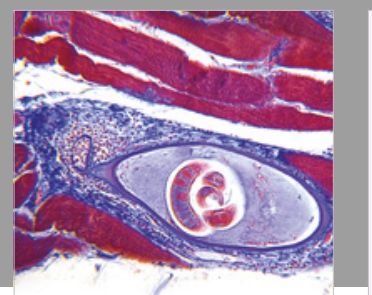

Gastroenterology Research and Practice

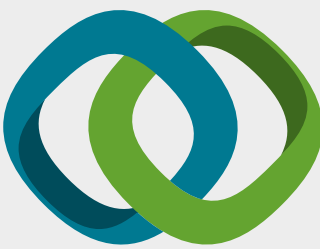

\section{Hindawi}

Submit your manuscripts at

www.hindawi.com
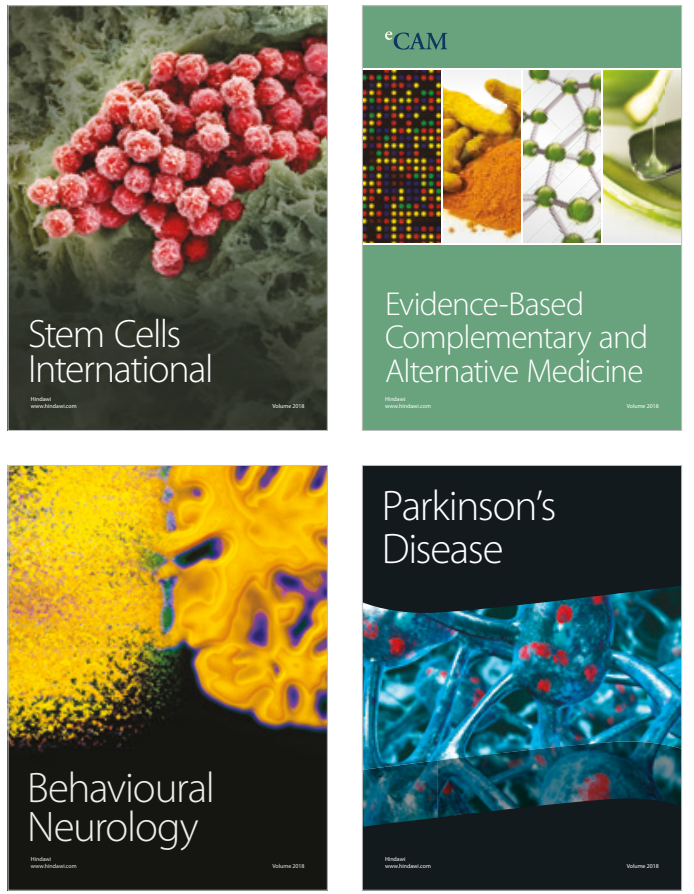

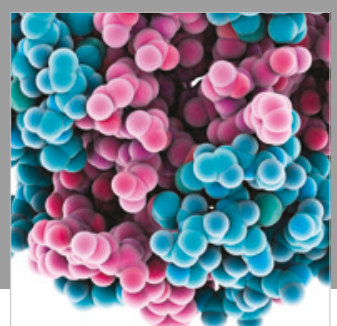

ournal of

Diabetes Research

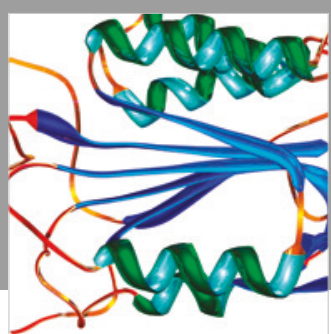

Disease Markers
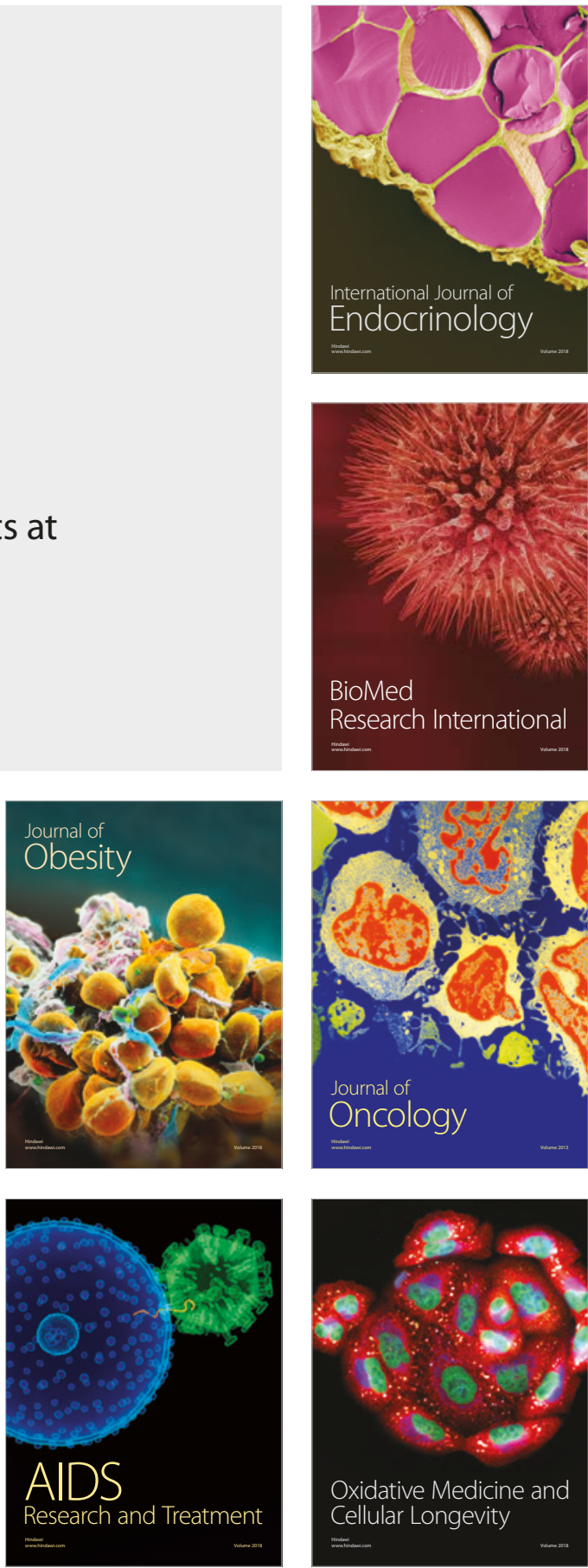